\title{
Management of domesticated boer goat (Capra hircus) and free ranging kudu (Tragelaphus strepsiceros) in a production system
}

\author{
D Furstenburg, $\mathrm{H}$ Coetsee, D Swart
}

Roodeplaat Grassiand Institute, Agricultural Research Council, Private Bag X 05, Lynn East, 0039, South Africa

Kudu play an important economic role in integrated game and goat farming systems within the Valley Bushveld of the Eastern Cape of southern Africa. Goat production is affected by competition for browse by free ranging wild herbivores (kudu, bushbuck (Tragelaphus scriptus) and common duiker (Sylvicapra grimmia)). Subsequent deterioration of the habitat due to browsing caused by game is often not taken into consideration in determining stocking rates and forage condition.

Within a 3000 ha game-fenced ranch with 69 goat fenced camps, 2500 twig clusters were marked on five highly preferred browse species at five different height classes including all utilized browse strata. The clusters were monitored at bi-monthly intervals for twig length, number of leaves and signs of browsing. The goats followed a monthly rotational browsing programme through a 14 camp cycle, while game movement was unrestricted. An aerial game census was conducted annually. Triangular radio tracking was used to monitor the movement of the kudu. In vitro digestibility (Engels and van der Merwe, 1967, S Afr J Agric Sci, 10, 983-995), of 10 available browse species was determined using fresh rumen fluid of two kudu and two goats as innoculum.
Kudu showed a 2.6 to $5.0 \%$ higher digestibility of the dietary browse than goats. Goats browse preferentially between 30 and $120 \mathrm{~cm}$ plant height whereas kudu browsed mainly between 120 and $200 \mathrm{~cm}$. When Ca $50 \%$ of the available browse within easy reach has been utilized, goats started to browse at higher and lower levels beyond the preferred range, up to $180 \mathrm{~cm}$, overlapping with the kudu. Kudu browsed lower than $120 \mathrm{~cm}$ only when available browse became inadequate at the preferred higher levels. Kudu avoided the same locality as goats. When goats occupied a specific camp kudu move out and will return only after goats were absent, for at least 3 weeks. Thus kudu can consequently be forced to move and utilize specific areas of rested browse strata as a result of the goat rotational grazing system. Therefore in a mixed kudu and goat farming system rotational browsing by kudu of specific vegetation strata can be achieved.

By stocking conservatively with goats and kudu and with rotational management so as to utilize less than $40 \%$ of the available browse at either feeding stratum, kudu and goats will not be in dietary competition and can be compatible in a farming system. 